\title{
Cultivando cuerpos, modelando masculinidades
}

\section{Cultivating Bodies, Modelling Masculinities}

\author{
Begonya Enguix \\ Universitat Oberta de Catalunya. Barcelona
}

\section{RESUMEN}

Este artículo explora las relaciones entre cuerpo, género y sexualidad, y analiza cómo se construyen discursos sobre cuerpos particulares en situaciones cotidianas. Utilizando imágenes publicitarias y fotografías procedentes del trabajo de campo de la autora y las narrativas corporales evocadas por ambas, junto con las narrativas obtenidas mediante entrevistas en profundidad, se analizan los códigos discursivos y las convenciones mediante las que la masculinidad se vehicula. Esos códigos explicitan la estrecha vinculación entre cuerpo, género y sexualidad. El cuerpo masculino -objetivo de este trabajo- se construye mediante elementos marcadores de la alteridad sexual y marcadores de género que están fuertemente ligados a lo corporal (como el gender-crossing y la hipergenerización) y exponen los límites de los géneros y los cuerpos al mostrar cómo estos se modelan y resignifican en contextos particulares. Estos procesos dan lugar a la conformación de modelos hegemónicos y contramodelos con un fuerte componente de género que sustentan y/o resisten los cánones de belleza masculina.

Palabras Clave: Masculinidad, Género, Representación, Hegemonía.

\section{SUMMARY}

The present work explores the relationships between body, gender and sexuality and analyzes how the discourses on particular bodies are constructed in everyday life. We do so through the analysis of advertising images, of photographs from our own fieldwork, through the narratives evoked by them and also through data obtained during in-depth interviews. Through the analysis of the discursive codes and the conventions of masculinity, we examine the close association between body, gender and sexuality. The masculine body is constructed through marking elements of the sexual otherness and gender that are strongly linked to the body (like gender-crossing and hypergenderization) and that expose the limits of genders and bodies, showing how the latter are constructed and acquire meaning in particular contexts. These processes give rise to the formation of dominant models and counter-models with a strong gender component which maintain and/or resist the male model of beauty.

Key Words: Masculinity, Gender, Representation, Hegemony. 


\section{INTRODUCCIÓN ${ }^{1}$}

El cuerpo, como vehiculador de discursos que nos hablan de lo individual, lo social y lo simbólico, es el objetivo de este trabajo en el que se pretende explorar las relaciones entre cuerpo, género y sexualidad centrándome en los cuerpos masculinos, en sus usos, prácticas y representaciones.

El cuerpo masculino ha sido objeto de una creciente cosificación (Rohlinger 2002) que podemos relacionar tanto con la visibilización y empoderamiento de las sexualidades no hegemónicas como con la creciente sexualización de las sociedades occidentales (Paasonen et al. 2007; Attwood 2009). Lo sexual es una parte fundamental en la construcción del sujeto posmoderno. La constitución del cuerpo masculino como objeto de deseo por otro cuerpo masculino le sitúa en las intersecciones entre lo normativo y lo estigmatizado, y como lugar en el que se ejercen procesos de dominación y subordinación, discursos de poder y resistencia. La materialidad de esos cuerpos que ya no tenemos sino que somos, se construye hoy como base de nuestras identidades, como nexo con lo inmaterial y como elemento de valoración moral. Nuestro cuerpo, nuestra presentación ante los otros, va más allá de lo aparente: presenta y representa nuestro ser.

Los trabajos clásicos sobre el cuerpo (de Mauss a Goffman), junto con el impulso del feminismo y las discusiones recientes sobre la identidad, el deseo y la subjetividad corporal han situado el cuerpo en una posición central en el pensamiento actual (Sabido 2010; Pedraza 2003; Howson 2005; Langman 2003). El análisis de Foucault sobre las disciplinas corporales (1984) como medio de control ha influido a un gran número de pensadores, como Grosz y Butler. El cuerpo se ha constituido como fundamental para la conformación de las identidades modernas y las teorías de la agencia (Butler 1990). Es también locus privilegiado de y para el consumo (Baudrillard 1974). La relación entre cuerpo, identidad y consumo (Giddens 1994; Turner 1984; Featherstone 1982), mediada por el uso de "artefactos" simbólicos como el vestido, sitúa a la apariencia del ser físico (the visible self) como un elemento fundamental del estatus social (Shilling 2005: 2).

\footnotetext{
${ }^{1}$ Este artículo — que consideramos como la primera fase de un trabajo futuro- hubiera sido imposible sin la colaboración de los participantes. Vaya aquí mi agradecimiento por su entusiasta colaboración. También agradezco a M. Brox el material que me ha proporcionado y a Lula Criado Sánchez, Image Stylist y Fashion Analyst de Frontrow su asesoramiento en moda y en tendencias. Este trabajo ha sido realizado en el marco del proyecto de investigación de I+D+I La presentación social del cuerpo en el contexto de la globalización y la multiculturalidad (SEJ2007-60792).
} 
El título de este trabajo juega con la etimología de los términos "cultivo" y "cultura", puesto que ambos términos proceden del latín colere. Colere, según Williams (en Moreno Feliu 2010: 86) significaba habitar, cultivar, proteger y honrar con adoración o culto. La palabra "cultura" adoptó el significado principal de cultivo o cuidado. En francés antiguo, la palabra utilizada para designar la "cultura" era couture hasta principios del siglo XV. En aquel momento deviene culture y el mismo término se adopta en inglés. La posterior utilización del término "couture" para designar la costura, supone una vinculación de lo corporal con lo cultural mediante el vestido. El juego entre costura, cultura y cuerpo es fundamental para este trabajo en el que nos preguntamos cómo los cuerpos quedan "Cosidos" con sus significados sociales para construir la propia imagen...

En consecuencia, debe deducirse del título que cuando hablamos del cultivo del cuerpo partimos de una perspectiva en la que se relacionan la incorporación (es decir, la inscripción en el cuerpo en el sentido nietzscheano y butleriano) de los significados sociales sobre la masculinidad y la sexualidad, con su culturalidad y su cuidado.

\section{CUERPO, MASCULINIDAD, SEXUALIDAD}

En este trabajo consideramos que las disposiciones de género y de sexualidad "Son constitutivas más que completamente derivadas de la estructura social" (Mc Call en Skeggs 1997: 16), y que esas disposiciones tienen en el cuerpo uno de sus principales dispositivos, si no el principal. Como Pedraza (2003: 21) afirma, "el orden social más ligado al cuerpo es el del sexo".

Los cuerpos, en tanto construcciones sociohistóricas (Trumbach 1993; Laqueur 1994; Butler 1993) informan y son informados por las distintas configuraciones del sistema simbólico sexo/género/sexualidad vehiculando y performando identidades. Así, los cuerpos fueron decisivos cuando se consideraba que los homosexuales eran "hermafroditas" (Trumbach 1993); cuando se buscaron en el cuerpo señales de travestismo u homosexualidad (siglos XVII y XVIII) y cuando el primer movimiento homosexual (creado en Alemania por Hirschfeld y Ulrichs en 1897) consideró que los homosexuales eran "un alma de mujer en cuerpo de hombre". Los cuerpos son también centrales para la constitución de las identidades fluidas y performadas queer.

El cuerpo no es un "ser", sino un límite variable, una superficie cuya permeabilidad es regulada políticamente, una práctica significante en el campo cultural de la jerarquía de género y la heterosexualidad (Butler 1990: 189)².

\footnotetext{
${ }^{2}$ Las traducciones son de la autora.
} 
Por estos motivos, el análisis del cuerpo en relación con el género y la sexualidad y su mutua constitución ha sido un campo privilegiado de investigación ${ }^{3}$. Un análisis como el que aquí se propone, que explore la relación entre cuerpo, masculinidad y sexualidad y pretenda vincular lo teórico con usos, prácticas, experiencias y discursos concretos, necesariamente será incompleto: cuerpo, género y sexualidad están interseccionados de múltiples maneras entre sí y por otras categorías sociales relevantes (entre ellas la clase, la edad o el grupo étnico) que no podemos aprehender en su totalidad, dados los objetivos concretos del trabajo. Las múltiples intersecciones que pueden llegar a producirse entre estos sistemas de categorización desbordan nuestro modo de clasificación, aunque pretendemos reflejar —en la medida de lo posible - el juego entre lo evocado, lo normativo y lo desregulado y su in-corporación a nuestros imaginarios (sobre los géneros, sobre el sentido, sobre el orden y el desorden, sobre la emoción).

Los conceptos de habitus y hexis de Bourdieu (1997; 2005b), que ponen en relación las estructuras del mundo y las disposiciones de los agentes mediante la socialización de los cuerpos (Galak 2011), han sido muy utilizados para analizar los cuerpos sociales y han sido aquí una importante fuente de inspiración. Partimos de la producción de una

definición diferenciada de los usos legítimos del cuerpo, sexuales sobre todo, que tiende a excluir del universo de lo sensible y de lo factible todo lo que marca la pertenencia al otro sexo, para producir ese artefacto social llamado un hombre viril o una mujer femenina (Bourdieu 2005b: 37).

Esos "artefactos sociales" son el producto de habitus diferenciados que somatizan las relaciones de poder. Bourdieu entiende las convenciones sociales como algo que anima los cuerpos, que - a su vez- ritualizan estas convenciones por medio de prácticas. En este sentido, el habitus se forma, pero también es formativo: constituye una forma tácita de performatividad (Bianciotti 2011: 81) .

También han sido fuente de inspiración los paradigmas performativos de Judith Butler, que desvelan y revientan los límites normativos de la matriz heterosexual y la estructura imitativa del propio género y su contingencia (Butler 1990: 187).

\footnotetext{
${ }^{3}$ Vayan como muestra los trabajos de Foucault (1984), Laqueur (1994), Bourdieu (2005), Howson (2005), Weeks (1987), Vázquez y Moreno (1997) y buena parte de las teorizaciones feministas y queer.

${ }^{4}$ Bianciotti (2011) lleva a cabo un análisis sobre las prácticas de seducción de jóvenes universitarias en Córdoba (Argentina) donde combina las aproximaciones de Butler y Bourdieu.
} 


\section{MASCULINIDAD/ES}

En los años 90 emergieron con fuerza los estudios sobre la masculinidad $^{5}$, fundamentales como referente de este trabajo. Entre los autores más destacados, R. W. Connell merece una especial atención por su teorización de la masculinidad hegemónica (1995). Con este concepto Connell fragmentó la categoría "hombre" y mostró que los hombres formulan elecciones discursivas particulares a partir de un inventario cultural disponible y aceptable de comportamientos masculinos (Herrmann 2007).

La masculinidad — "la forma aceptada de ser de un varón adulto en una sociedad concreta" (Gilmore 1994: 15) — se define fundamentalmente en términos negativos (los hombres no son niños, ni mujeres, ni homosexuales): la identidad masculina se ha construido principalmente como rechazo de la feminidad y de los valores que la configuran estereotipadamente (Alberdi y Escario 2007: 69; Gilmore 1994). La masculinidad es a la vez un lugar de relaciones de género, el conjunto de prácticas a través de las cuales los hombres y las mujeres se sitúan a sí mismos en relación con el género, y los efectos de dichas prácticas en las experiencias corporales, en la personalidad y la cultura (Weeks en García Cortés 2004: 39).

Interseccionadas por el poder, la producción y la emoción, las masculinidades son múltiples y relacionales. No obstante, con frecuencia se habla de una "identidad masculina" — presentada de forma esencialista, reduccionista y universalizadora - que en realidad se refiere a una "masculinidad hegemónica" que persigue la reproducción del patriarcado a partir del repudio de lo femenino, que se mide a través del poder, el éxito económico, y la posición social y que tiene en el control de las emociones, la osadía y la agresividad sus atributos. Una masculinidad difícil de alcanzar, como Goffman anticipaba en los años 60:

Según el consenso general, en Estados Unidos, el único hombre que no tiene que avergonzarse de nada es un joven casado, padre de familia, blanco, urbano, norteño, heterosexual, protestante, que recibió educación superior, tiene un buen empleo, aspecto, peso y altura adecuados y un reciente triunfo en los deportes... todo hombre que no consiga llenar cualquiera de estos requisitos se considerará probablemente - por lo menos en algunos momentos- indigno, incompleto e inferior (Goffman 1968: 150).

Entre los autores que profundizan en el concepto de masculinidad

\footnotetext{
${ }^{5}$ Véanse, por ejemplo, Connell (1995; 1997), Seidler (2007), Kimmel (1987 y 2000), Mosse (1996), Vale (1996) y List (2005), y como antecedentes, Brandes (1991) y Gilmore (1994).
} 
hegemónica destacan Demetriou (2001) y el propio Connell (2005)6. Demetriou introduce un grado mayor de complejidad en el término considerando, desde un análisis basado en Gramsci y Bhabha, que "la masculinidad hegemónica no es solo una configuración blanca o heterosexual de las prácticas sino un bloque híbrido que vincula prácticas de diversas masculinidades para asegurar la reproducción del patriarcado" (2001: 337).

El proceso de formación de los bloques de hibridación opera, según Bhabha, más mediante la negociación que mediante la negación, es decir, mediante intentos de articular, apropiarse e incorporar (más que negar, marginar o eliminar) elementos distintos o aparentemente opuestos (pragmatismo dialéctico) (Demetriou 2001: 349). Esta misma idea de hibridación aparece en el texto de Connell (2005) donde afirma que la masculinidad hegemónica no es un patrón unitario, sino un bloque histórico donde se entrelazan muchos patrones, siendo esa hibridación — resultado de un proceso constante de negociación, traducción y reconfiguración- la mejor estrategia para conseguir la hegemonía externa (Connell 2005: 844). Estos procesos de negociación, traducción y reconfiguración tienen lugar tanto intergéneros como intragéneros, siendo la sexualidad un elemento fundamental en la constitución de los bloques y la performación del género un elemento de suma importancia, como veremos.

Aunque el cuerpo está aquí oculto, no existen ni género ni sexualidad fuera del cuerpo: por tanto el cuerpo, como el género y la sexualidad, tiene también un papel predominante en la conformación de esos bloques híbridos e históricos. Si nuestra comprensión del género informa la sexualidad y la sexualidad confirma nuestro género (Fracher y Limmel 1995 en Rohlinger 2002: 62) ambos existen en y desde nuestros cuerpos.

\section{GÉNERO/S Y ESTILO/S}

La masculinidad — más asociada al cuerpo que a la mente- es muy representacional (Rohlinger 2002: 62) y el cuerpo masculino, ese artefacto social de Bourdieu, se manipula, performa y expresa físicamente sobre todo mediante la fuerza física y la habilidad atlética, es decir, fundamentalmente mediante el músculo. También se expresa mediante el consumo y el adorno: fuerza, consumo y adorno constituyen al cuerpo en un objeto y sujeto de deseo cuyo valor de intercambio "aumenta cuanto más desea, es deseado y se aproxima a las imágenes idealizadas de la juventud, la salud, la

\footnotetext{
${ }^{6}$ Véanse también Coles (2009), Lusher y Robbins (2009), Pringle (2005) y Sheff (2006).
} 
buena forma física y la belleza" (Featherstone 1999: 177). Por eso, los contextos homoeróticos, donde los cuerpos masculinos son objeto y sujeto de placer, son privilegiados para analizar la conformación de los bloques históricos —e híbridos- de masculinidades.

Músculos, placer, atractivo, masculinidad, vello, adornos corporales, vestido... son algunos de los elementos que intervienen en la construcción cultural de "estilos" paradigmáticos relacionados con los cuerpos masculinos y gays. Estos estilos ponen a prueba los límites en las definiciones sociohistóricas del sexo, el género y la sexualidad, y los cuestionan (Enguix 2010). Los estilos e identidades actuales son el producto de procesos de desmedicalización y de reapropiación y resignificación de los cuerpos antes etiquetados como "desviados", gracias a la emergencia de los movimientos sociales de los 60 y en particular del movimiento gay (ahora LGTB) ${ }^{7}$. Esos procesos, como sugiere Kimmel, siempre se entienden mejor a través del prisma del género, y en particular de la masculinidad (Levine: 1998: x) . $^{8}$

El género es un criterio clasificatorio relevante en el universo homosexual como muestra, entre otros, Levine en su texto Gay Macho (1998: 56 y ss.). Levine narra cómo una homosexualidad masculina fuertemente generizada en la década de los 50 en EEUU (vinculada con el afeminamiento o con la hipermasculinidad) evoluciona hasta el Gay Clone. Este modelo, que emerge a finales de los años 60, resuelve las tensiones entre la masculinidad butch (ruda) y la masculinidad feminizada gracias a la mediación de un movimiento gay que "reorganizó las estrategias de presentación de la cultura del closet" (Levine 1998: 57) rechazando el afeminamiento y vinculándolo con la homofobia; se consideró entonces que los gays no eran errores, ni desviados, sino hombres reales y en sus estilos presentacionales reflejaron su conformidad con las normas tradicionales de la masculinidad que tanto habían luchado por conseguir (Levine 1998: 57). Aunque se desarrollaron distintos estilos de presentación, todos jugaban con el género: "después de todo, el género es lo más determinante del estilo" (Levine 1998: 57), aunque el género es difícil de objetivar, una presencia con frecuencia ausente, en términos lacanianos (Howson 2005). Mediante la conformidad de género con la masculinidad tradicional el clon — vaqueros, camiseta ajustada o camisa a

\footnotetext{
7 Véase Levine (1998) para una descripción de la importancia del activismo en la puesta en escena; Rohlinger (2002) para una enunciación de las posibilidades que emergen con la liberación y Enguix (2010) para el análisis de la reapropiación, resignificación y generización de los cuerpos.

${ }^{8}$ Como veremos, esta idea es compartida por nuestros informantes: recurren constantemente al género como criterio fundamental de clasificación de los cuerpos que se les muestran.
} 
cuadros, botas, bigote, pelo corto-, cuya definición Levine centra más en el género que en el atuendo, buscaba resolver la crisis de identidad que supone ser similar a los heterosexuales pero tener el estigma de una orientación sexual distinta en las ciudades estadounidenses de los 70 y los 80 .

La reivindicación de la masculinidad homosexual se condensa en los cuerpos, que son "cultivados" para significarla; las imágenes ideales se "cosen" a los cuerpos hasta constituirlos. Como Coles apunta (2009: 38), inspirándose en Shilling y Bourdieu:

El cuerpo masculino se representa como personificación de las imágenes dominantes de la masculinidad [...] los músculos se han equiparado con los ideales masculinos hegemónicos de la fuerza y el poder; la escasa grasa corporal se asocia a ser activo y disciplinado; la juventud se vincula con la salud y la virilidad. De este modo, los hombres con cuerpos que resumen la masculinidad hegemónica y que se ajustan al ideal cultural (lisos, musculosos, jóvenes) tienen el capital físico más valorado en el campo de la masculinidad.

La valoración del cuerpo musculoso como un cuerpo atractivo ha dado lugar a un estilo hegemónico de gay que entronca con las representaciones de la masculinidad que han sido frecuentes desde la Antigua Grecia (Mosse 1996; García Cortés 2004; Langman 2003; Moore 1997)9. Los códigos discursivos y las convenciones para significar la masculinidad en las revistas actuales refuerzan este ideal, que evoca la fuerza y la dominación. Igual que en la antigua Grecia, los deportistas de hoy son iconos de belleza: Rafa Nadal y Gerard Piqué son la imagen publicitaria de Armani y Mango (respectivamente). La asociación del entrenamiento físico, el deporte y la disciplina con lo masculino es tan fuerte que "la mujer deliberadamente musculosa cuestiona las nociones dominantes de sexo, género y sexualidad... provocando contestación y conflicto, ansiedad y ambigüedad" (Schulze 1997: 9).

Otros elementos de importancia para significar el género y generar un estilo corporal son el vestido, los adornos, el uso de maquillaje y el vello (Enguix 2010) ${ }^{10}$. El vestido, la indumentaria que utilizamos, nos sitúa como

${ }^{9}$ Este estilo que proyecta autoridad y omnipotencia coexiste después de la segunda Guerra Mundial con la aparición de movimientos que explicitan la ambigüedad física y sexual (García Cortés 2004: 51).

${ }^{10}$ Es evidente que estos elementos no agotan las posibilidades de generización y que dan lugar a múltiples combinatorias; aún así son destacables, puesto que emergen con frecuencia como significantes corporales de género en las narrativas de los informantes. La constitución de estilos basados en patrones particulares de consumo lleva a hablar de un creciente proceso de "Comodificación" de las identidades (Holt y Griffin 2003: 421), o de una visibilidad gay en la cultura de los bienes "que vincula la reproducción del patriarcado con la del capitalismo" (Demetriou 2001: 351). 
miembros de grupos particulares, de estilos de vida que están interseccionados por el género. Una rápida mirada a la historia de la moda (véase Blackman 2009; Arnold 2001) nos muestra no sólo su naturaleza cambiante sino su potencial transgresor y transformador. La existencia de convenciones generizadas en el vestir se evidencian, por ejemplo, en la condena histórica del cross-dressing (vestirse como el sexo contrario). La masculinidad, los cuerpos masculinos y el modo en que los cubrimos y mostramos son todas ellas construcciones sociohistóricas que transmiten información sobre el sujeto. El diseñador Alexander McQueen, fallecido en 2010, era consciente del poder que el vestido tiene en la conformación de la identidad. En la exposición que el Metropolitan Museum de Nueva York le dedicó en el verano de 2011, sus vestidos se acompañaban de algunas de sus frases, algunas tan elocuentes como estas: "Cuando ves una mujer vestida de McQueen, la ropa tiene una dureza que la hace parecer poderosa. Aleja a la gente... quiero empoderar a las mujeres, que la gente tenga miedo de las mujeres que visto" "11.

A pesar de los intentos de asentar en el mercado líneas de maquillaje masculino (Jean Paul Gaultier fue precursor en lanzar al mercado una gama), el maquillaje entendido como instrumento de transformación y perfeccionamiento facial, es aún conceptualizado como una cosa de mujeres. Se han generalizado los productos de tratamiento masculinos (hidratantes, mascarillas, etc.), y algunos adolescentes varones utilizan productos de maquillaje (como el eye-liner), pero el último referente colectivo de uso de maquillaje masculino es la realeza europea dieciochesca. Los hombres utilizan maquillaje en contextos festivos o como disfraz, al estilo de lo que ocurría en las molly-houses británicas (Trumbach 1993) pero no forma parte del imaginario de "lo masculino".

El vello corporal y facial sí están culturalmente relacionados con lo masculino, hasta el punto de que en determinadas épocas, y hasta recientemente, todos los hombres mostraban vello facial ${ }^{12}$. La figura de la mujer barbuda, en mayor medida que la de la mujer musculosa, simboliza lo nonatural, lo monstruoso, lo transgresor ${ }^{13}$. Si bien en Occidente la depilación femenina es una práctica habitual, los últimos diez años han presenciado un auge de la depilación masculina (sobre todo en zonas como la espalda, las nalgas, el pecho) que curiosamente coexiste con el culto al vello corporal ejemplificado por los osos (bear). Los osos son hombres gays que se

\footnotetext{
11 Recogido por la autora.

12 Véase Reyero (1996) y Enguix (2011).

13 Véase Pedraza (2009) y Enguix (2011).
} 
caracterizan por tener unos cuerpos que no se corresponden con los ideales hegemónicos de belleza gay, y por tener un discurso fuertemente generizado —que simultáneamente cuestiona y reproduce las normas de la masculinidad hegemónica (Hennen 2005: 25). Consideran el vello corporal y facial como elementos distintivos (Hennen 2005; Hennen 2008; Sáez 2010b; Wright 1997$)^{14}$.

Los osos están de moda. La gente cree que está bien cuestionar el cuerpo perfecto, yo soy un seguidor y creo que rompen el estereotipo gay aunque he de reconocer que ese estereotipo es muy atractivo. Cuestionar la imagen que la gente tiene de los gays como jóvenes, musculosos y preocupados por su aspecto, es una pequeña revolución y es la clave de su éxito (entrevista T.P., feb. 2010).

La asociación entre la población general de "lo gay" con unos cuerpos determinados que se corresponden con unos cánones de belleza estrictos (musculosos, bien torneados) conlleva que, con frecuencia, los osos pasen desapercibidos dado su aspecto de "chicos normales" y su actitud de "hombre heterosexual normal" (Clarkson 2008: 380).

Según Sáez (2010a) los osos y los leather son las "dos subculturas relacionadas con la representación de la masculinidad" que encontramos en la actualidad (aunque su origen se remonta a los años 50 en el caso leather y a los 80 en el caso bear). El tipo de vestido y el vello corporal son sustantivos para la definición de ambas. Los leather —un estilo más situacional que el de los osos - se caracterizan por el uso de indumentaria de cuero negro inspirada en los moteros, la reivindicación de la masculinidad y determinadas prácticas sexuales relacionadas con el BDSM.

El discurso y las prácticas de ambas subculturas producen un efecto paradójico alrededor de las representaciones simbólicas y políticas de lo masculino: la cultura leather potencia los cuerpos y las actitudes hipermasculinas, llevando el disfraz del cuero hasta un exceso que vuelve paródica la propia construcción de la masculinidad. La cultura de los osos intenta construir un cuerpo y unos valores "naturales" a partir de algunos valores tradicionales de la masculinidad: la barba, el vello corporal, el cuerpo fuerte, grande u obeso, la virilidad, la ausencia de afeminamiento... Ambas estrategias suponen dos formas políticas de cuestionamiento de la masculinidad, a partir de una reinvención artificial basada en el exceso (Sáez 2010a: 1).

Si bien todas las posiciones en el continuo que podemos dibujar entre lo masculino (de lo "normal" a lo "hipermasculino") y lo femenino (estereotipa-

\footnotetext{
${ }^{14}$ Donahue y Stoner (en Wright 1997: 149-156) elaboran un sistema de clasificación detalladísimo que combina estos elementos con la cantidad (mayor o menor) en que están presentes.
} 
do, marginado, minoritario) pueden ser interpretadas tanto en términos de reproducción como de subversión del imaginario social, lo cierto es que los estilos masculinos se han erigido en "homonormativos" (dando incluso lugar a lo que se ha dado en llamar una "identidad gay transnacional" por su uniformidad) (Cf. Altman 1996). Como apuntaba Levine, estos estilos comparten los valores asociados con la masculinidad hegemónica (agresividad sexual, independencia) para quizá legitimar su masculinidad gay, retornando a los "gays femeninos a un armario de aniquilación simbólica" (Clarkson 2008: 380). $\mathrm{Y}$ sirven para trazar "fronteras de masculinidades gays dominantes y subordinadas" (Coles 2009: 39), mediante la performación del género.

En definitiva, la existencia de múltiples intersecciones entre los géneros, los cuerpos, los estilos y las disciplinas apuntan a la existencia de bloques híbridos de masculinidades y discursos en los que las hegemonías internas (Demetriou 2001) tienen fuertes contenidos de género. Estas hegemonías y subordinaciones pueden depender del contexto (Jefferson 2002) aunque, como veremos, las hegemonías que se construyen sobre lo atractivo son bastante uniformes.

\section{ALGUNOS APUNTES METODOLÓGICOS}

Nos presentamos y representamos ante los otros mediante lo que Goffman (1987) denomina "el arte de manejar las impresiones" (el proceso mediante el que los individuos manipulamos la interpretación de una situación social). En esas situaciones sociales nos situamos como personajes y como actuantes generizados, y esa puesta en escena produce una co-construcción del género en situaciones ordinarias. Nuestro interés en captar esas dinámicas junto con la certeza de que resulta mucho más fácil elaborar narrativas corporales sobre otros que sobre uno mismo, nos llevó a optar por utilizar la fotografía como técnica de evocación (elicitation) (Collier 2001) dejando que los informantes opinaran espontáneamente sobre fotografías de cuerpos masculinos. Las fotografías humanas, al estabilizar las cualidades y características de los cuerpos, facilitan el análisis (Rohlinger 2002: 62). Son un buen modo, además, de ejercitar las propias identidades y competencias culturales para su interpretación (Armstrong y Weinberg 2006).

Basándonos en Gender Advertisements (1979), el canónico trabajo de Goffman, y en otros trabajos que analizan la relación entre los géneros y los medios de comunicación ${ }^{15}$, decidimos utilizar imágenes publicitarias;

\footnotetext{
${ }^{15}$ Rohlinger (2002); Gibson (2004); Locke (1997); O’Barr (2008); Ragusa (2003); Saucier et al. (2008).
} 
Los medios proporcionan imágenes de los roles adecuados, de la conducta de género adecuada, e imágenes del estilo, apariencia e imagen adecuados para el sujeto contemporáneo. La cultura de los medios da recursos para la identidad y nuevos modelos de identidad en los que la apariencia, el estilo y la imagen sustituyen a la acción y el compromiso como constitutivos de la identidad, del propio ser (Kellner en Locke 1997: 121).

Los anuncios publicitarios son un buen instrumento para estudiar los valores dominantes porque los publicistas generalmente posicionan sus productos en relación con los símbolos y los valores culturales (Rohlinger 2002: 63). Como la publicidad aspira a llegar a segmentos de población lo más variados posibles y la segmentación de los públicos es cada vez mayor, ofrece distintos modelos de realidad -en este caso de cuerpos masculinosque hemos intentado que estuvieran representados en la muestra. Por ello, seleccionamos los anuncios inseridos en dos revistas de tendencias - Tendencias y H Magazine — , dos femeninas —Cosmopolitan y Glamour —, tres masculinas - L'Uomo Vogue, GQ y Obmygod!) — y cinco publicaciones gay (Shangay Express, Shangay Style, Odisea, Qué Guay, Shanguide), todas ellas en sus ediciones de junio-julio 2011 ${ }^{16}$. El País Semanal dedicó un número a la asociación entre cuerpo y deporte que también fue consultado ${ }^{17}$.

Muchas publicaciones gays subsisten gracias a la publicidad de locales destinados al público LGTB. La importancia que en algunos de ellos se presta a los códigos en el vestir (dresscode) hizo que visitáramos las páginas web de los siguientes locales:

The Hoist, Londres: http://www.thehoist.co.uk/Home/DressCode Eagle club, Madrid: http://www.eaglespain.com/es/Dresscode.html Nuncadigono, Valencia: http://www.nuncadigono.es/fiestas.html Dakota, Valencia: www.bardakota.com Dark alicante: http://www.dark-alicante.es.tl/ Men to Men, Sevilla: http://mentomenbar.blogspot.com/p/bar-staff.html El hombre y el oso, Sevilla: http://www.elhombreyeloso.es/18

Basándonos en trabajos anteriores (Enguix 1996; 2000; 2009; 2010; 2011) y en un prolongado trabajo de campo etnográfico sobre cuerpos, masculinidad y sexualidad, llevamos a cabo una primera selección de imágenes,

${ }^{16}$ Ohmygod! es, según nuestras informaciones, la única revista de venta en kioscos y de pago dirigida al público gay que existe en la actualidad, tras la desaparición de la revista Zero.

${ }^{17}$ El País Semanal, núm. 1817, domingo 24 julio 2011.

18 Todas las páginas fueron consultadas el 23 de junio 2011 y nuevamente el 1 de septiembre de 2011. 
buscando captar la "negociación cultural" de significados a la que alude Gledhill (en Van Zoonen 1994: 8), una negociación inspirada en la co-construcción (medios-audiencias) de los discursos mediáticos. El sistema de codificación/ decodificación de Hall (1980) es una guía útil para acercarse a este proceso de negociación.

Si los anuncios son un buen instrumento para analizar los discursos dominantes, el Orgullo LGTB es un buen medio para analizar las narrativas corporales mediante las que los participantes se visibilizan, y exponen su "presentación de sín siguiendo sus propios códigos. Este contraste nos hizo incluir en la selección final ejemplos de ambos contextos (seis fotos de anuncios y ocho procedentes del archivo sobre las celebraciones del Orgullo LGTB de la autora). Catorce imágenes es un número adecuado para mostrar la variabilidad de modelos existentes (cuerpos atléticos y cuerpos que no lo fueran, cuerpos que evocan lo masculino, lo femenino y lo andrógino). La fuente de las imágenes no figuraba en la presentación que se envió a los informantes.

Pretendíamos provocar narraciones lo más libres posibles que nos acercaran a los discursos que los informantes construyen sobre cuerpos masculinos para analizar cómo se descifran los mensajes encriptados que las imágenes evocan y cómo entroncan tanto con los imaginarios sociales como con las realidades imaginadas. Se buscaba explorar las categorías que se ponen en funcionamiento para la interpretación de cuerpos concretos. Y por ello nuestra intervención fue mínima, dando a los informantes solo unas mínimas directrices ${ }^{19}$. Aunque conozco personalmente a la mayoría de los informantes, decidí que era conveniente tener los relatos por escrito y que fueran elaborados en un contexto libre de intromisiones o sugerencias por mi parte. Elaboré una presentación en powerpoint con las fotos que envié por correo electrónico a los informantes con las directrices comentadas. Han colaborado en este trabajo diez hombres gays — de entre 27 y 54 años-. Los datos se completan con los obtenidos en cuatro entrevistas en profundidad y con otros procedentes de mi trabajo de campo.

La intención inicial era llevar a cabo este trabajo con hombres homo y

${ }^{19}$ Este es el texto que acompañó a las imágenes: "Este trabajo tendrá por título 'Cultivando Cuerpos'. En él pretendo analizar la presentación del cuerpo masculino desde la perspectiva de los géneros (masculino y femenino) y prestando atención a todos los elementos que utilizamos diariamente para comunicarnos unos con otros (dresscode, vestido, complementos, maquillaje, abalorios). La selección de fotos que incluyo consta tanto de fotos tomadas por mí en diferentes celebraciones del Orgullo como de anuncios publicitarios recientes en los que se muestran modelos masculinos. Os pido que comentéis cada foto". 


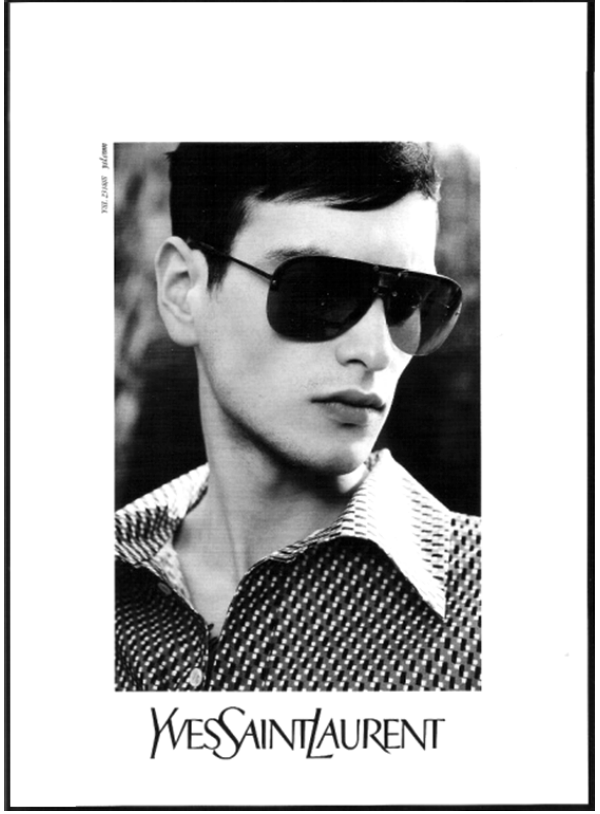

Figura 1.-Ambigüedad. Fuente: L'Uomo Vogue, julio de 2011. heterosexuales para, en una fase posterior, hacerlo con mujeres homo y heterosexuales. La elección de hombres homosexuales como informantes constituye así una primera fase de una investigación sobre cómo se construyen y constituyen los discursos corporales sobre lo masculino, que será más amplia. Aunque entronca con mi trayectoria de investigación, su elección no obedece a una visión esencialista y apriorística que afirme que los hombres homosexuales tienen una mirada particular y diferente. No obstante, es evidente que las imágenes masculinas son para los hombres homosexuales a la vez objeto erótico y modelo en el que se refleja el sujeto y su deseo. Es probable por ello que su mirada sobre otros hom-

bres, junto con el conocimiento de ciertos códigos, nos proporcione más información sobre la relación entre cuerpo, género y sexualidad que en otros casos.

De todos los medios consultados, seleccionamos cincuenta anuncios publicitarios en los que aparecieran cuerpos masculinos, lo que nos dio una idea de los distintos modelos de hombre que actualmente se nos presentan, y elaboramos un esquema —necesariamente simple y simplificado- basado en tres modelos: el andrógino, el estándar y el hipermasculino.

El recurso a la ambigüedad en moda como signo de modernidad, transgresión y radicalidad, es decir, la androginia, no es nada nuevo. El diseñador franco-tunecino Hedi Slimane es un buen ejemplo de ello, como también lo son los modelos Iris Strubegger (pionera en adoptar un look andrógino antes que la española Bimba Bosé) o Andrej Pejic, un it-boy girl ${ }^{20}$. En las revistas femeninas aparecen muy pocas imágenes masculinas en la publici-

${ }^{20}$ Se considera que este modelo serbio-australiano expresa la androginia perfecta habiendo desfilado tanto en colecciones de hombre como de mujer. Ver http:// www.trendencias.com/modelos/iris-strubegger-un-rostro-distinto; http://www.hedislimane. 
dad, pero en las revistas de tendencias o masculinas, observamos un acusado sesgo a mostrar cuerpos jóvenes y ambiguos, vestidos con colores pastel y poses que Goffman denominaría "femeninas" (mirada perdida, toque evanescente (Goffman 1979) ${ }^{21}$ (fig. 1).

El look hipermasculino — que predomina en las revistas gays- lo encarnan a la perfección la publicidad de la marca Dolce and Gabbana o recientes anuncios de Swatch como el que reproducimos (fig. 2).

Existe un modelo que hemos denominado "estándar" (los informantes lo etiquetan como "normal") que está representado por anuncios como el de Montblanc o Calzedonia (ver figs. 3 y 7 ).

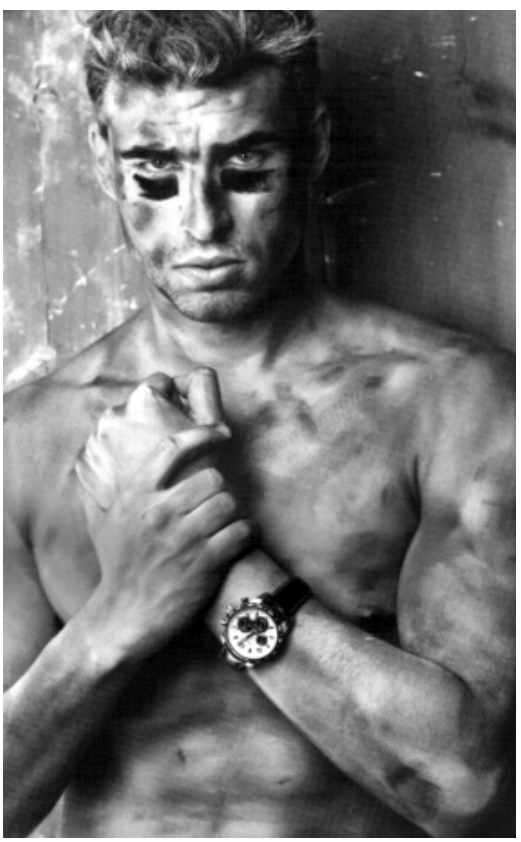

FIGURA 2.- (incluida en la muestra). Hipermasculinidad. Fuente: Obmygod, junio de 2011.

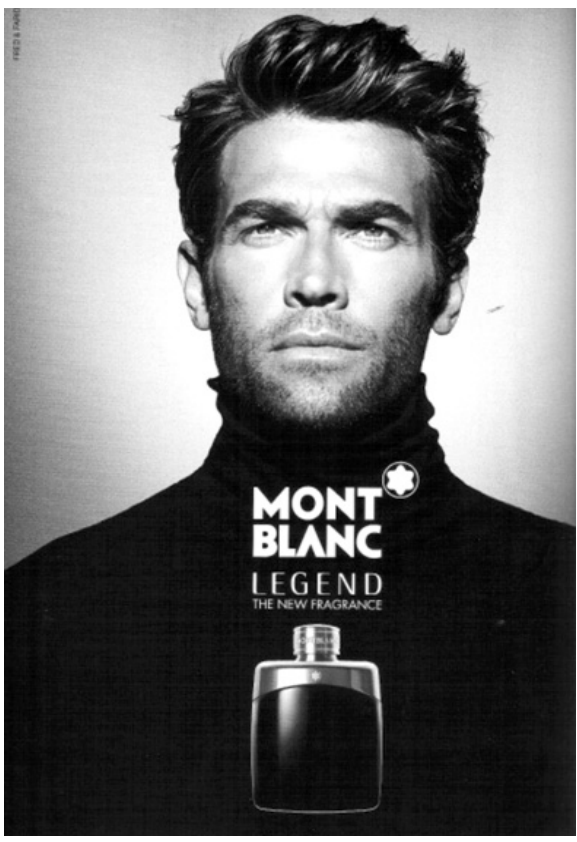

FIgura 3.-Estándar. Fuente: L'Uomo Vogue, julio de 2011.

com/; http://www.elpais.com/articulo/portada/Andrej/Pejic/elpepisupep3/20110107 elptenpor_6/Tes y http://www.elpais.com/articulo/agenda/top/model/hombre/elpepigen/ 20110605elpepiage_2/Tes http://www.trendencias.com/modelos/andrej-pejic-el-fenomeno-delnuevo-it-boy-girl (todas consultadas el 10 agosto 2011).

${ }^{21}$ Todas las imágenes, y más las vinculadas con la moda, entroncan con los conceptos de clase y gusto que por limitaciones obvias del trabajo no podemos desarrollar aquí (Bourdieu 1988). 
En la muestra que enviamos a los informantes se incluyeron ejemplos de estos tres modelos procedentes tanto de las publicaciones consultadas como del archivo fotográfico sobre el Orgullo LGTB ${ }^{22}$.

\section{CUERPOS PROPIOS Y AJENOS: LA MIRADA SITUADA}

Los modelos andróginos, tan presentes en la publicidad actual, tienen su equivalente en las presentaciones en el Orgullo y llegan al límite en las expresiones drag. En la muestra escogida se incluyeron ejemplos tanto de androginia como de drag, además de una foto que mostraba a un participante en la manifestación del orgullo con barba y gafas de espejo, cuerpo disciplinado y que combinaba un atuendo indexado como masculino y femenino (Kerrell 1992): gorra de policía, tirantes, guantes y cinturón de piel negra, sobre un torso desnudo y dos cadenas y pendiente plateados. La parte inferior de su indumentaria consistía en un eslip rojo, liguero y medias negras.

Según los informantes, el estilo andrógino (etiquetado como drag, androginia y fetiche), suele conjugar rasgos faciales dulces, corta edad, poco músculo y ausencia de vello. Lirio de Agua etiqueta a estos hombres como "Modelis, pijamitas, pequeñas, blandos" ${ }^{23}$, aludiendo así a su afeminamiento y a su edad. Este estilo no es considerado atractivo por ningún informante: "la mayoría de los gays admiten no sentirse atraídos por gays tan afeminados. En mi caso tampoco" (Judes). Incluso cuando combina un cuerpo "leído" como femenino con complementos militares (fig. 4), el cuerpo se superpone a los complementos y se obvian (sorprendentemente) esos complementos - elementos bastante recurrentes que nos remiten al concepto de autoridad y normatividad - así como cualquier referencia al juego de identidades. Esta "masculinidad ligera" (Miguel) llega a desconcertar a los informantes: "No sé si son tías o tíos, femeninos, no me llama la atención" (Ojitos verdes).

${ }^{22}$ En este artículo se explicita qué figuras formaron parte de la presentación que se envió a los informantes mediante la aclaración "incluida en la muestra".

${ }^{23}$ Según Alex Rei (J.L), creador de este término "Los pijamitas son chicos pequeños, con cierto aire aniñado que te apetece llevártelos a casa, ponerles un pijamita, acostarles y contarles un cuento. Que te apetece proteger. Los te-hostio son todo lo contrario, los chulos de barrio, con cierta agresividad que inspiran cierto temor, los bakalas, vamos. Tengo amigos que me dicen que son dos extremos y que, claro, por ser un poco pijamita o un poco te-hostio me gustan todos, pero no es verdad, jajaja. Ahora, creo que son dos tipos de chicos que nos gustan a muchos homosexuales." http:// www.gaybarcelona.net/personajes/alexrei.htm (consulta 31 agosto 2011). 
Esta misma desorientación la encontramos en las narraciones sobre el drag: «es maja, se ha currado el traje que es muy bonito todo de Coco Chanel, será un tío, pero va a ser que no" (Javito). El drag se asocia a la "diversión" y se etiqueta como falto de atractivo, dándose por sentado el escaso éxito sexual de esa presentación: "no ligarán" (kko). También se alude a la incomodidad que genera

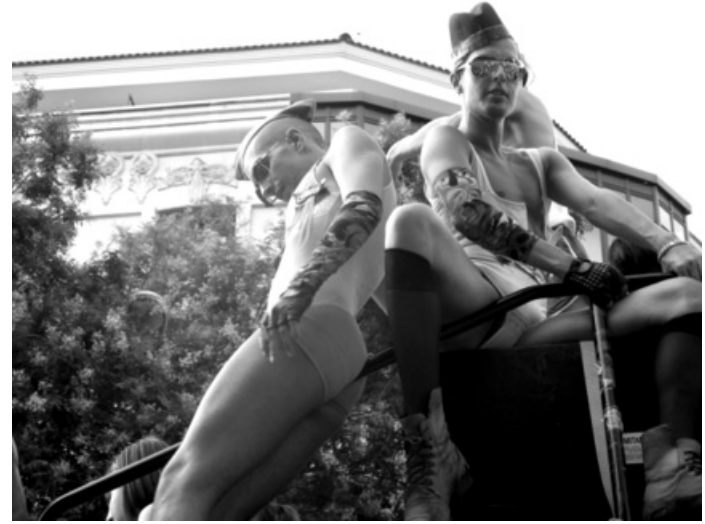

Figura 4 (incluida en la muestra).--Manifestación Estatal del Orgullo LGTB, Madrid, julio de 2011. Foto de B. Enguix.

"Si no conozco a la persona que hay debajo" (Miguel).

MR basándose en una de las fotografías de la muestra, hace una lectura subversiva y reivindicativa de ese estilo:

tres travestidos clásicos con todos los atributos de femineidad de concurso de belleza: pelazo, tacones, joyas, maquillaje... Representan un poco la imagen que nuestros padres tenían del homosexual como invertido vestido de mujer. Por eso, al tener tantísima pluma, son los que más joden con su presencia a los más prejuiciosos, a todos los que te toleran siempre que pases desapercibido y "que no se te note". Personalmente, me siguen pareciendo los más dignos de admiración.

Los mismos argumentos de diversión, falta de atractivo y de éxito sexual se aplican también a la foto del policía con eslip y liguero a la que aludíamos: su protagonista "no ligará porque no es atractivo" (kko). Su "fetichismo indefinible" (Judes) es criticado: es "una mujer, además es pasiva" (Javito). Pero también es interpretado en clave de subversión y transgresión de los roles:

este "gay polifacético" que mezcla elementos de dos tendencias estéticas diferentes: la gorra, la barba y los tirantes de rollo leather o así, con las bragas con liguero en la más pura tradición travesti. Resulta refrescante por lo iconoclasta del asunto..." (MR).

En el caso de los anuncios que mostraban el modelo andrógino (figs. 5 y 6) ("modelis, pijamitas, blando, efebo" según Lirio de Agua) los protagonistas son considerados "asexuados" (kko) y, por tanto, faltos de atractivo y deseo sexual. Se destaca su juventud, su delgadez, su estética (sus cejas 


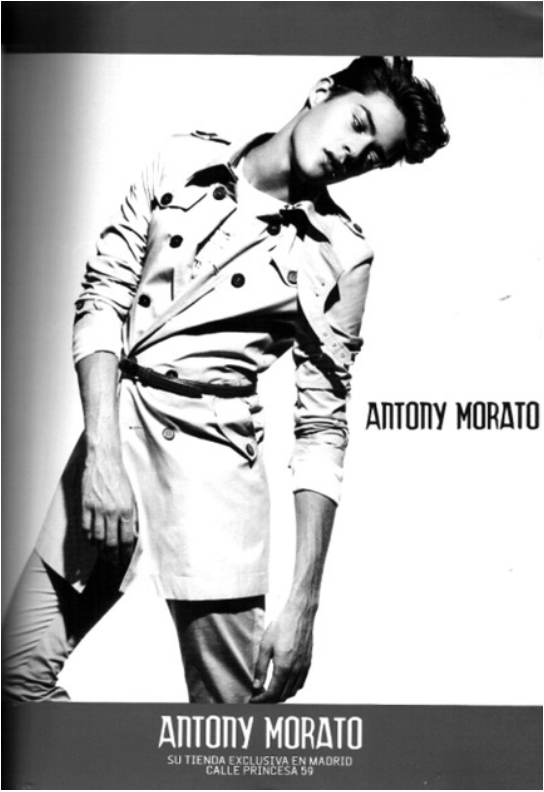

FIgURA 5 (incluida en la muestra).Fuente: Obmygod, junio de 2011

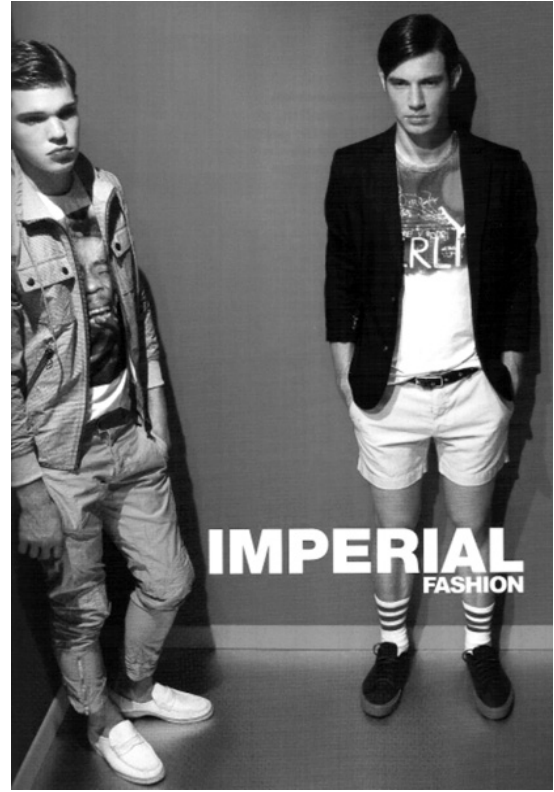

FIgURA 6 (incluida en la muestra).Fuente: L'Uomo Vogue, julio de 2011.

depiladas) y su actitud desvalida que mueve al "deseo de protegerlo y ponerle un piso" (Lirio de agua).

Estas imágenes entroncan con la fragilidad femenina que caracterizaba a la publicidad de los años 70 según Goffman (1979). Estamos ante un "modelo andrógino y lánguido con toneladas de estilo. ¿Compensa su aparente falta de virilidad con elegancia y languidez?" (MR). Este modelo andrógino, en definitiva, es "demasiado moderno para mi gusto, demasiado joven para mi gusto, demasiado niño para mi gusto, poco masculino para mi gusto" (Juan Pa).

No obstante, existe en ese estilo algo que inquieta a los informantes: "Van muy modernos, pero no tienen aspecto masculino, van un poco en plan rollo gay pero bueno no tienen porqué ser gays por llevar esa ropa" (Juan Pa). Su ropa, los colores fuertes y el cuidado de su imagen los ubica en un contexto en el que su "pluma" "vuelve a identificar homosexualidad y moda" (MR), una pluma que se inscribe más en el uso de "colores fuertes que en su depilación o ropa o pose» (X). En este caso,

El hábil publicista ha diseñado un look teenager que (aparte de tener valor para ponérselo) puede cautivar tanto a sus compañeras adolescentes de "al salir de clase" 
como a sus profesores. En cuanto al resto de sus compañeros heteros, su actitud puede ir desde considerarlos nenazas hasta apedrearlos (Lirio de Agua).

En contraste con estas re-presentaciones andróginas, nuestra muestra incluía dos fotos de presentaciones más "estándar", una de las cuales ha sido etiquetada casi unánimemente como "normal" (fig. 7).

Este anuncio de Calzedonia representa, según los informantes, al hombre más masculino de la muestra (tres informantes), el más natural, el más atractivo (en ocho casos) y el más ansiado: "Quiero un hombre así en mi vida, mi prototipo de hombre, el más masculino" (Ojitos Verdes), es el "novio ideal" (Javito). Este hombre "guapo y viril" (MR) — "lo más masculino que corre por este álbum de fotos" (Josemi) — "se cuida lo suficiente, pero sin demasiada dependencia dejando que la natura-

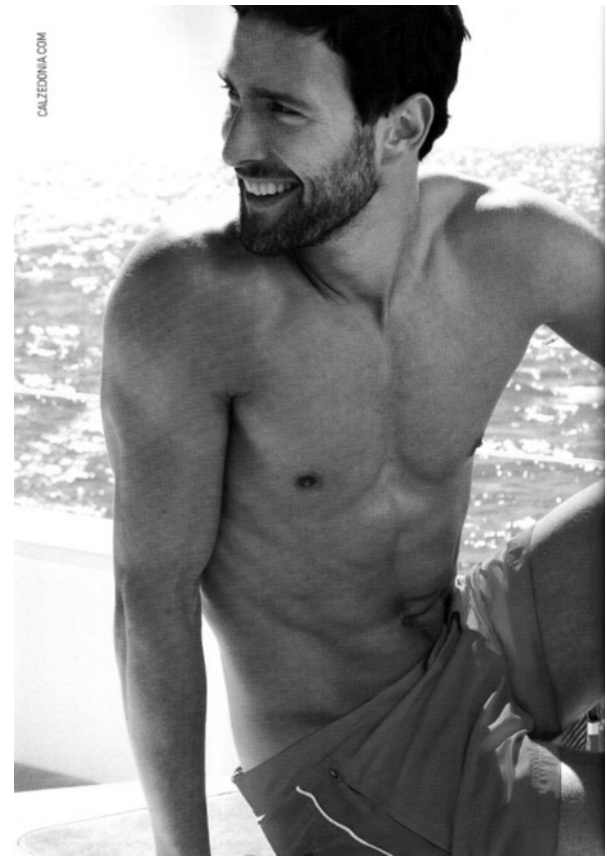

FIGURA 7 (incluida en la muestra).Fuente: L'Uomo Vogue, julio de 2011. lidad sea su mejor aliada" (kko).

Su "naturalidad atrae y seduce", al tiempo que interroga su sexualidad:

El típico chico guapo que le gusta a todo el mundo (uno incluido) y que no responde a ningún prototipo "gay" por lo que su etiqueta más aproximada es la de "normal". Esta ausencia de connotación (homo)sexual suele estar asociada a la heterosexualidad, o al menos a su apariencia (Lirio de Agua).

Representa el modelo de hombre hetero guapísimo y clásico que tanto atrae y seduce (Judes).

A pesar de ir depilado, "la barba le otorga la dosis justa de masculinidad" (X). Los términos clave mediante los que se construye el atractivo parecen ser la "naturalidad", la "dosis justa" (de músculo, de barba, de depilación) pero también su sonrisa y el contexto en el que ha sido fotografiado que aparecen en las narrativas como temas recurrentes.

También consideramos que podía etiquetarse como "natural" o "estándar" la imagen de este chico fotografiado en un contexto rural, desenfadado y con una abundante barba (figura 8). No obstante, su barba se considera 


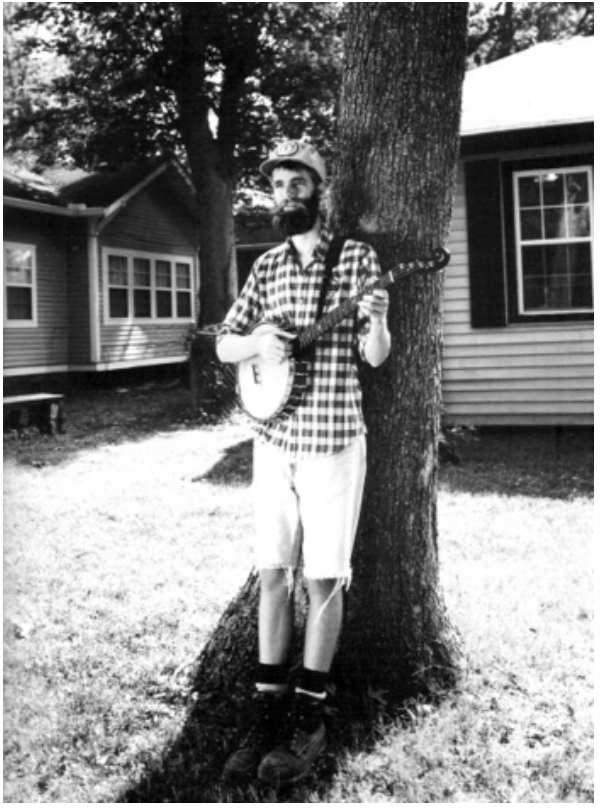

FiguRA 8 (incluida en la muestra).Fuente: H Magazine, julio de 2011.

excesiva: "Chico modernete y gracioso, cuya barba y emplazamiento rural podrían disimular su posible pluma" (MR) y nadie le etiqueta como masculino.

El salto de lo material a la sexualidad, como antes había ocurrido respecto al atractivo y/o la potencia sexual, también se lleva a cabo en este caso, al leer en clave homosexual este anuncio publicado en una revista de tendencias. Aunque la imagen sirve para introducir, por primera y única vez en el discurso de los informantes, el tema de las ficciones identitarias como construcción sociocultural.

Supongo que el look pretende unir la reivindicación del hippy de los 70 (que este chico conocerá por las fotos de sus padres) con la languidez de los modernos pop y la reivindicación "Osa" de la apariencia masculina "normal" (barbas y camisas a cuadros) pero al final, al estilizar el look y las convenciones del rollo oso, este chico pone en evidencia que ese rollo (¿cultura?) de naturalidad, convivencialidad y jovialidad y campechanería, etc. es una representación tan elaborada y fabulada como los looks de las dominettes de la foto 2 (Lirio de Agua) ${ }^{24}$.

El estilo masculino o hipermasculino se constituye generalmente a partir de la conexión entre masculinidad y músculo, y el modelado de estilos "hipermasculinos" a través del disciplinamiento del cuerpo es evidente en muchas narrativas.

El vello, la grasa acumulada en la barriga, las manos venosas y grandes, los brazos musculados son signos de masculinidad desde mi punto de vista, rasgos que diferencian lo masculino de lo femenino claramente. La actitud y mostrar el torso desnudo lo mismo, es impensable ver a una mujer con el torso desnudo sin que sea objeto de deseo (X).

Esta reflexión sobre una fotografía que mostraba a un hombre de entre 50 y 60 años, musculado y con el torso desnudo, vincula cuerpo y deseo

\footnotetext{
${ }^{24}$ La foto 2 a la que se refiere Lirio de Agua es la figura 4 en este trabajo.
} 
pero la edad funciona aquí como elemento importante: si el músculo convive con una edad avanzada, las narrativas loan los esfuerzos del protagonista al tiempo que cuestionan su éxito, medido en términos de atractivo: "Muy cachas por arriba, pero tiene michelín. Vestido y de lejos lo mismo me gustaría, se le ve pluma" (Javito). El paso de un estigma a otro es rápido: del michelín al disgusto y al afeminamiento solo va una coma.

Si el músculo es excesivo, resulta atractivo, pero sacrificado:

Dieta talibán y estricta, gimnasio prácticamente todos los días y en algunos casos complementos proteicos, anabolizantes... La estética de la foto, como dioses del Olimpo es muy típica de las publicidades de Gaydar, Infinita, Matinée... Son los cuerpos más deseados y más buscados... (Judes, sobre la figura 9).

El reconocimiento de ese esfuerzo lleva a hablar de "cuerpo diez", "deseable" y "atractivo": un "modelo a imitar por muchos heterosexuales, de cómo tiene que ser un hombre de verdad" (Miguel). Un modelo deseable, deseado y buscado, tanto por homosexuales como por heterosexuales (figuras 9 y 10).

La combinación de músculo y homosexualidad ha dado lugar a dos términos emic, "musculoca" (utilizado por dos informantes para referirse al protagonista de la figura 9) y "mariclón" (que algunos informantes utilizan

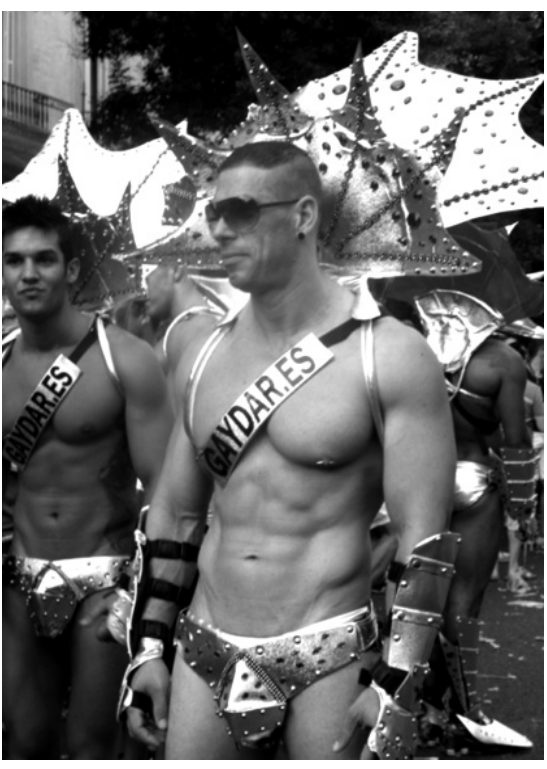

FIGURA 9 (incluida en la muestra).Manifestación Estatal del Orgullo LGTB, Madrid, julio 2011. Foto de B. Enguix.

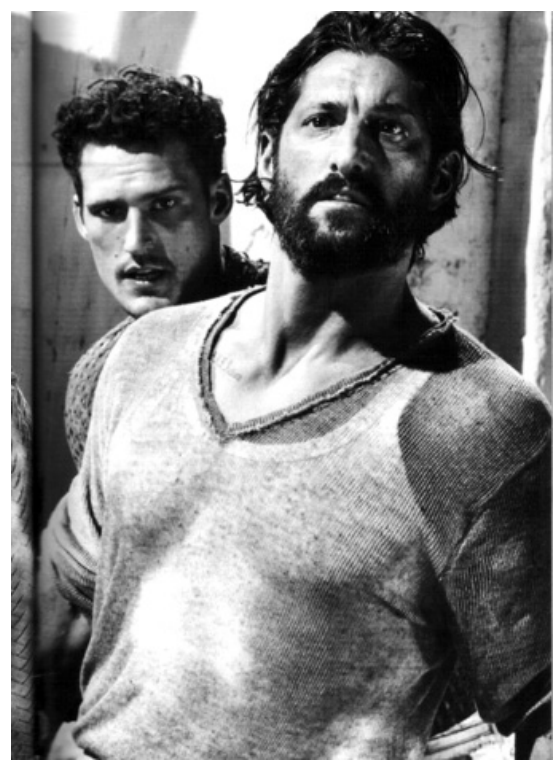

Figura 10 (incluida en la muestra).Fuente: Ohmygod, junio 2011. 
para referirse tanto a este modelo como a los osos $^{25}$ ). Si descomponemos estos términos, observamos que suponen un etiquetaje negativo que se construye en base al cuerpo ("muscu"), la sexualidad ("mari", "loca"), el género ("mari", "loca") y la falta de originalidad ("clón"). Pero también son un ejemplo del juego entre expertos y profanos: siendo gays quienes los utilizan, está claro que lo que se critica no es la sexualidad sino la exageración — que se resignifica como feminización- y la uniformización. La superposición de músculo y afeminamiento sólo es posible entre los expertos, conocedores de los códigos. En cambio, para los profanos, este es el modelo hegemónico de gay (construido/ difundido también por los medios, además de por los propios gays) y difícilmente sería etiquetado y/o criticado en términos femeninos.

A pesar de todo, ante estos cuerpos los informantes se posicionan claramente como sujetos deseantes, considerando este estilo como el más deseable y deseado: "Como oí una vez 'tú consigue que vengan las musculocas y todos los demás vendrán detrás'” (Lirio de Agua). El deseo va más allá de lo sexual: "podría ser el novio ideal para presentar a los amigos y que se mueran de envidia" (Miguel, sobre la figura 10); este modelo es "el tipo que muchos deseamos tener al lado cuando despertemos. Desde luego que no es el prototipo de gay que piensan muchos heterosexuales, pero sí es muy frecuente en el ambiente, sobre todo en el mundo oso" (Miguel). Su masculinidad se pone en relación con su fuerza y su rudeza: "Rudo, fuerte, machote, protector... de los que te defiende en una pelea" (Judes).

De hecho, como muestra la figura 11, los ganadores de los concursos de belleza gay responden a este estilo de cuerpo.

Como comentamos, la combinación de cierto punto de gordura con el vello corporal también es leída como signo de masculinidad y considerada atractiva: es el caso de los hombres que

han pillado el punto "OsO" en todo su "clasicismo" y no les falta un detalle: gordura la justa, sombreros campesinos, camisas a cuadros de manga sisa camionera, muñequeras de cuero, el baile del gorila y las gafas de espejo u oscuras, que me estoy dando cuenta que son un código transversal (Lirio de Agua).

Las narrativas también evocan la masculinidad en la postura ( la barba, la postura y la cara de mala leche son remasculinos", X), la actitud y la mirada.

Aunque algunas fotos mostraban hombres con arneses y otros símbolos de autoridad (abundantes tanto en las manifestaciones del Orgullo, como

\footnotetext{
${ }^{25}$ Respecto a una foto de la presentación que aquí no reproducimos y que mostraba osos, Miguel nos dice: "Es el tipo de hombre que te encuentras en los bares de osos. Hay muchos como estos, sin personalidad, otro tipo de mariclones" (Miguel).
} 
en la iconografía gay en general), los informantes se han detenido mucho más en comentar los cuerpos que en comentar los complementos. Aún así, el uso de pulseras de cuero mereció comentarios de MR por su relación con los roles sexuales.

Como contrapunto a los modelos anteriores, presentamos la foto de un hombre que desfilaba "sin complejos" en shorts rojos con abdomen prominente y escaso vello corporal. Etiquetado inequívocamente como poco "sensual", sin embargo su actitud fue definida como "desafiante", "masculina" e "irónica", llegándose incluso a aventurar cómo sería su vida: "A este le pasa lo contrario que al de la foto anterior, duerme en casa

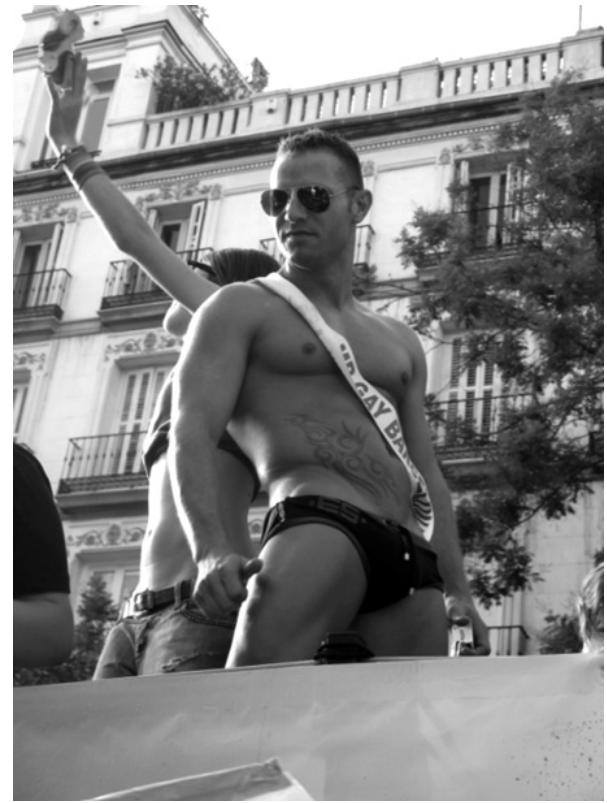

FigurA 11.-Mr. Gay Barcelona 2010. Pride Barcelona, junio 2010. Foto de B. Enguix. acompañado todos los días" (kko).

\section{DESCIFRANDO CUERPOS, IMAGINANDO CUERPOS}

Nos encontramos — nos son ofrecidas a diario- múltiples posibilidades de modificación y de disciplina corporales para dar una imagen que creamos que nos re/presenta de algún modo ante el mundo, mediante el ejercicio de unas acciones que derivarán en interacciones particulares, es decir, en formas particulares de sociabilidad. En un contexto marcado por la fluidez, los antiesencialismos, la desnaturalización y la glosa de la plasticidad, el uso de fotografías como técnica de evocación parece ser un recurso útil para visibilizar el género en el cuerpo, no solo en el ritual o en los momentos cruciales, sino en lo ordinario (Gómez 2008: 6).

A pesar de la fluidez, sorprende encontrar en las narrativas analizadas una estrecha vinculación entre cuerpo y género desde una visión bastante estereotipada y que se articula en torno al continuo femenino-masculino. La omnipresencia de las disposiciones de género — propias y ajenas- es evidente en el lenguaje utilizado para etiquetar las imágenes: mariclón, musculoca, mamarracha, pequeñas, mujer, hombre, diva, blando... no son más que algunos de los términos que hemos encontrado para indexar los 
cuerpos presentados. Las narrativas y las etiquetas destilan la pervivencia en el imaginario de lo que Pleck llamaba el "rol masculino tradicional" caracterizado por la fuerza física, la falta de emotividad, la fuerza, la invulnerabilidad y cierta agresividad o impulsividad (en Levine 1998: 13).

Aún afirmando la subversión de los binarismos jerárquicos mediante ciertas prácticas paródicas, los límites de la performance parecen remitir a un habitus que intenta perpetuarse solo permitiendo la resignificación en el marco del orden dado de las cosas y sin posibilidad transformadora fuera de él. Un habitus que no genera ni la reproducción mecánica y simple de los condicionamientos iniciales, ni una libertad incondicionada. Un habitus que facilita capacidades infinitas de actuar, pero con límite (Bianciotti 2011: 80-81). El límite marcado por lo viril y lo femenino. No obstante, cierto juego entre el imaginario social y lo imaginario es evocado a veces, como cuando, para referirse a una foto que muestra a tres travestidos, nos dicen: "pienso que detrás de este disfraz me pueda encontrar a un machote de pelo en pecho, jeje (aunque sería difícil)" (Juan Pa).

La mayor o menor masculinidad de la imagen, tal como se desprende de las narrativas, se construye básicamente mediante lo corporal (sin adornos) y no mediante el vestido. Los informantes desnudan los cuerpos. En cambio, el vestido y el adorno (tomando en consideración el colorido, que ha aparecido en varias narrativas, y el maquillaje) son fundamentales para la construcción de lo femenino, lo ambiguo y lo andrógino. El vestido deviene fundamental también en el caso de estilos particulares (leather, osos), que se identifican mediante atuendos propios, aunque rara vez se habla aquí de los arneses como elemento de masculinidad. Esto es hasta cierto punto lógico teniendo en cuenta que, tratándose todos ellos de cuerpos masculinos, sólo se destaca en la narrativa lo excepcional, lo que marca una diferencia ostensible, es decir, lo que feminiza o sitúa al individuo como miembro de un grupo o "comunidad" particular. Aún así es digna de consideración la poca atención prestada a la utilización de símbolos de autoridad que, como contrapartida, son un recurso muy utilizado como dresscode de locales particulares. El cuerpo, más que el vestido, deviene el elemento significante por sí solo en todos los casos.

Para la construcción de lo masculino y su interpretación como tal, fundamentalmente intervienen el músculo y el vello facial y corporal, reforzando así la estrecha asociación que ha existido históricamente entre músculo, vello y masculinidad tradicional; son también frecuentes las referencias a la postura y la actitud ${ }^{26}$.

${ }^{26}$ Goffman (1979) concede a la postura y la actitud un papel importantísimo en relación con la comunicación de los significados de género. 
Las narrativas de los informantes saltan con fluidez del cuerpo al género y a la sexualidad (presentando a los modelos como masculinos o femeninos, pero también como asexuados, sexuales, homosexuales o heterosexuales), con una facilidad que se fundamenta en el conocimiento de los códigos visuales que las imágenes presentan. Cuerpo, género y sexualidad parecen constituir un sistema indisociable que se aprehende globalmente a partir de cuerpos particulares. Aún así, a pesar de ese conocimiento compartido de los códigos, la perfección en la performance de algunas imágenes (en particular las drag) induce a algunos informantes al error de pensar que lo que tienen ante sí son mujeres y no hombres.

El conocimiento de los códigos se basa en diferencias a veces sutiles y difíciles de objetivar entre lo adecuado y lo excesivo. Si bien lo atractivo se construye como más cercano a lo adecuado, lo sexualmente deseable está tan próximo a lo "adecuado" como a lo "excesivo". Por ejemplo, si comparamos dos hombres musculados, siendo uno de ellos "normal" y el otro "musculoca", la categoría "atractivo" se utilizará para el "normal" mientras que la categoría "deseable" se utilizará para ambos. El cuestionamiento de la masculinidad que el músculo excesivo trae aparejado (de ahí el término degradante "musculoca") le resta atractivo a esa presentación, pero no potencia sexual.

Ese salto fluido del cuerpo al género, a la sexualidad y a la actividad sexual (incluso a los roles sexuales) requiere la implicación activa del sujeto que mira para ir más allá de la mera descripción y está en relación con uno de los hallazgos más sorprendentes e inesperados de este trabajo: el posicionamiento del sujeto como activo ante las imágenes con una mirada claramente situada. Personándose como sujetos activos y deseantes, han sido muy frecuentes los comentarios personales sobre las imágenes: "me gusta", "no me gusta", "me atrae", "me lo llevaría a mi casa", "me cae bien", "quiero un hombre así en mi vida" no son más que algunos de los múltiples ejemplos de este posicionamiento del sujeto, del salto de la materialidad del cuerpo a la inmaterialidad de la emoción que la visión de ese cuerpo nos provoca. El cuerpo propio se posiciona como sexuado y deseante, situando al cuerpo del otro como deseable o no deseable en términos afectivos, eróticos o claramente sexuales. Los criterios representacionales o los aspectos puramente descriptivos están diluidos en las narrativas y aparecen entremezclados con la emoción que el cuerpo del otro suscita en el propio ${ }^{27}$. Una emoción teñida a veces de sexualidad hasta el punto de que, dado el

\footnotetext{
${ }^{27}$ Se combinarían aquí, como Mulvey apuntó en 1975, el instinto escopofílico (el placer de mirar a otra persona como objeto erótico), y, en contradicción, la libido del ego (que forma los procesos de la identificación) (en Nixon 2003: 318 y ss).
} 
contexto del trabajo y la propia sexualidad de los entrevistados, se leen todas las imágenes como si representaran hombres homosexuales o susceptibles de mantener una relación homoerótica. Tanto las fotos procedentes de nuestro trabajo de campo sobre las celebraciones del Orgullo como las de anuncios publicitarios, han sido interpretadas del mismo modo y utilizando los mismos códigos. El concepto de "hegemonía contextual" (Jefferson 2002) no es adecuado aquí, puesto que el contexto ha pasado a un segundo plano: los informantes toman las imágenes y las interpretan desde sus experiencias y subjetividades particulares sin tener en cuenta el contexto en el que y para el que fueron creadas. El sujeto que mira y desea es el centro de la imagen presentada que se convierte así en vehículo para la expresión de la subjetividad de quién mira.

Un tema recurrente en las narrativas es la edad: parece haber un consenso general — coherente por otra parte con los imaginarios sociales al respecto- según el cual "hay una edad apropiada para cada cosa". Mediante las alusiones a la edad (sobre todo la excesiva juventud), la perfección corporal, la cantidad de vello, la pose y la actitud, y el posicionamiento activo del sujeto ante la imagen desde su experiencia y su subjetividad, se construye una escala de atractivo que aparece claramente en las narrativas y que sitúa al hombre "natural" y al mismo tiempo con un cuerpo perfecto (fig. 7) como el más atractivo. Las imágenes que se consideran "masculinas" son valoradas positivamente, mientras que otros cuerpos más lánguidos o ambiguos son calificados como demasiado jóvenes, demasiado afeminados, dignos de protección o "demasiado modernos", y etiquetados como asexuados y faltos de atractivo. Lo mismo sucede respecto al drag: en las dos fotos en que aparece, se habla de diversión, pero nadie se posiciona personalmente considerándolo atractivo; es más, aparecen con frecuencia expresiones como "no van a ligar". Y lo mismo ocurre con quienes llevan disfraces, como el policía con liguero, otro tipo de drag, que suscita el mismo tipo de comentario. Sin embargo, otra clase de "disfraz", como el de los osos o los leather, no despierta este tipo de comentarios: su masculinidad es coherente con los esquemas de atractivo.

La construcción del atractivo en base al cuerpo (atlético), y al género (masculino) en estas narrativas reproduce los estereotipos homo y heterosexuales de gay atractivo que han llevado a hablar de "homonormatividad", es decir, de la existencia de unos cánones de belleza rígidos que se imponen en un mundo en el que ser y parecer atractivo es fundamental para la sociabilidad. Esta "homonormatividad" se procesa mediante mecanismos de regulación de las disciplinas corporales que son un ejemplo del control social de un grupo constituido por cuerpos deseantes y deseados, cuerpos buscados por el otro y cuerpos que buscan al otro. Por todo ello, si nos centra- 
mos en las narrativas analizadas, no parecen existir múltiples hegemonías: hemos encontrado discursos muy uniformes en informantes muy diversos (en edad, procedencia, formación y clase) respecto a la conformación de los gustos (Bourdieu 1988) y respecto a lo que consideran atractivo (que va desde lo "normal" — fig. 7-, al cuerpo potente de la figura 9). Las intersecciones y el espacio para el juego parecen no tener lugar en estas imágenes congeladas. Tampoco los modelos parecen ser permeables. El cuerpo masculino se define por su éxito sexual, enlazando así con la masculinidad tradicional: un éxito que parece vinculado, no sólo con los ideales estéticos de la Grecia clásica, sino con su ensalzamiento del justo medio. La imagen más loada (fig. 7) muestra la cantidad exacta de músculo y de barba, muestra un cuerpo que remite a los ideales clásicos, pero que no muestra ningún hieratismo ni impostación: sonríe y se muestra cómplice.

Las expectativas corporales se traducen en las narrativas en expectativas sociales sobre el éxito social y sexual del cuerpo mostrado (e imaginado por el espectador). Esas expectativas se basan sobre todo en el cuerpo, entendido como una superposición de elementos cuya suma va más allá de las partes y desborda lo material para inundar lo emocional, mediante la construcción de la categoría de "atractivo". Entre esas partes, encontramos el músculo y el vello, pero también la sonrisa: "Un tiarrón, muy guapo, con una sonrisa que ¡madre mía!, me he enamorado ${ }^{28}$. La tensión entre las partes más objetificadas y las menos objetivables de la "presentación de sín se resuelve con facilidad en unas narrativas que transitan y fluyen desde lo aparente a lo afectivo, lo erótico o lo moral con facilidad y en las que se afirman cosas como "parece buen tío"; "es natural", "me resulta simpático", "me parece divertido", "no parece que tenga las ideas claras" o "mucha pintura de guerra, pero a mí este que no me defienda ante el peligro" acerca de imágenes congeladas. Esta fluidez constituye lo atractivo y lo deseable como un proceso cuya construcción es compleja, puesto que se basa tanto en la materialidad del cuerpo como en la invisibilidad del carácter — con mayor o menor preponderancia de estos elementos. Los extremos apuntados por Levine en la siguiente cita son posibles, pero también lo son otras combinatorias. Aunque, como él apunta y nuestro análisis corrobora, el género cumple un papel fundamental:

Eran mucho más importantes las partes del cuerpo objetivadas que, por ejemplo, el color de ojos o la sonrisa. Y olvidemos la conexión emocional o el origen social. Mientras que los hombres heterosexuales generalmente erotizan los atributos fe-

\footnotetext{
${ }^{28}$ Comentario de Juan Pa a la foto 7.
} 
meninos — sobre todo el tamaño del pecho- los hombres gays erotizan los masculinos. Cuánto más rudo (butch) más perseguido sexualmente... los hombres percibían a los otros como sexies mientras fueran machos. Nacionalidad y clase eran irrelevantes (Levine 1998: 86).

La uniformidad en valorar el cuerpo musculoso, la masculinidad y una puesta en escena "natural" parecen apuntar hacia la existencia de un canon de belleza hegemónico que atraviesa los géneros y las sexualidades, y nos lleva a cuestionar la existencia de modelos múltiples e híbridos que conformen bloques de hegemonía y subalternidad. La interiorización de ese canon parece ser unánime entre quienes comentaron las imágenes. La correspondencia del canon con lo culturalmente deseable lleva a quienes quieren ser atractivos a mirarse en el espejo que los modelos representan y a "representar" ese canon en la medida de lo posible y con las adaptaciones necesarias a sus posibilidades, mediante distintas estrategias que incluyen desde el cuidado del vestido hasta la práctica habitual del ejercicio físico (caso de la mayoría de informantes).

Este mapa sobre la construcción de lo atractivo y lo deseable, que partía de la interrogación por el cuerpo y la masculinidad, no estaría completo sin una referencia a los osos y a la importancia que ha adquirido su modo de presentación y política corporal en los últimos años. Aunque su existencia es cada vez más visible (lo que corroboran nuestras entrevistas y nuestras observaciones de campo) curiosamente fueron pocas las referencias a este estilo en las narrativas de los informantes (y estaban representados en la galería de imágenes). Basándonos en nuestro trabajo de campo previo, creemos que su visibilidad en los círculos de relación LGTB y sus discursos fuertemente corporales y generizados sí apuntan a la existencia de bloques híbridos en los que las hegemonías son contestadas y negociadas. Los osos, como los hombres de cuerpo perfecto y musculoso, ejemplifican y desvelan que los sujetos son lugares de poder (Butler en Bianciotti 2011: 80-81). De hecho, la confluencia de dos lógicas que parecían incompatibles, el oso y el músculo, ha dado lugar a un tipo de oso - musclebear - que combina atributos de una y otra (vello corporal en un cuerpo perfectamente musculado), introduciendo así nuevos elementos en el proceso dialéctico de las hegemonías y subalternidades masculinas.

En definitiva, consideramos que la hibridación de masculinidades corporalizadas y generizadas se expresa tanto en el cuerpo propio como en el ajeno, en el cuerpo vivido y en el deseado que, a su vez, es espejo en el que uno se mira. El juego entre ser, desear y ser deseado se encarna en modelos reales y/o ideales o inalcanzables. El juego entre todos esos cuerpos (el cuerpo que vemos, el que somos, el que desea y el que es (o 
quiere ser) deseado), permea las narrativas hasta el punto de evidenciar que los cuerpos propios y ajenos, fundidos en una misma mirada, condensan los imaginarios socioculturales sobre género y sexualidad, pero también discursos sobre lo apropiado, lo bello y el deseo, que emergen de las narrativas con una gran fluidez.

El género, los significados y disposiciones de género, se expresan en el cuerpo y permean toda nuestra vida social. Pero a partir de la materialidad de nuestro cuerpo y del cuerpo de los otros, emergen discursos sobre la emoción que esos cuerpos generan en la mirada ajena, sobre la sexualidad, sobre el comportamiento, sobre la moral. Las narrativas de los informantes trascienden el cuerpo y sus complementos y construyen el género como potencial de éxito social y sexual; en esa construcción interviene la emoción, el deseo, la experiencia de los informantes. Cuerpo, género, sexualidad y emoción se interseccionan para construir el ideal al que aspirar.

Aunque aquí no hemos podido analizar otras intersecciones, como la edad, la etnicidad, el activismo y las interacciones con las sexualidades normativas, creemos poder intuir que las masculinidades, como Demetriou (2001: 341) afirmaba, están atravesadas por luchas sobre los distintos tipos de capital que crean distinciones entre grupos hegemónicos y subordinados. En las masculinidades gays, como hemos visto a lo largo de estas páginas, entre esos tipos de capital destacan el capital físico - tener un cuerpo particular- y la conformidad con una masculinidad tradicional. Esos cuerpos masculinos particulares de los que hemos hablado, desbordan lo material y se adentran en lo simbólico para construir lo adecuado, lo emotivo, lo deseable y lo atractivo.

\section{BIBLIOGRAFÍA CITADA}

Alberdi, I. y P. Escario. 2007. Los hombres jóvenes y la paternidad. Bilbao: Fundación BBVA. Altman, D. 1996. "Rupture or continuity? The internationalization of gay identities". Social Text 48: 77-94.

Attwood, F. (ed.). 2009. Mainstreaming Sex. Londres: I.B. Tauris and Co.

Armstrong, E. A. y M. S. Weinberg. 2006. "Identity and competence: The use of culture in the interpretation of sexual images". Sociological Perspectives 49 (3): 411-432.

Arnold, R. 2001. Fashion, desire and anxiety. New Brunswick: Rutgers University Press.

Baudrillard, Jean. 1974. La sociedad de consumo, sus mitos, sus estructuras. Barcelona: Plaza y Janés.

Bianciotti, M. C. 2011. "Cuerpo y género: apuntes para pensar prácticas eróticas de mujeres jóvenes. Aportes de Judith Butler y Pierre Bourdieun. Relaces, Revista Latinoamericana de Estudios sobre Cuerpos, Emociones y Sociedad 6 (3): 25-38. Disponible en: http://www.relaces.com.ar/index.php/relaces/article/view/83/92 
Blackman, C. 2009. One Hundred Years of Menswear. Londres: Lawrence King Publishing. Bordo, S. 1997. "Reading the Male body", en P. L. Moore (ed), Building Bodies: 31-73. New Brunswick: Rutgers University Press.

Bourdieu, P. 1988. La Distinción. Madrid: Taurus.

Bourdieu, P. 1997. Razones prácticas. Sobre la teoría de la acción. Barcelona: Anagrama. Bourdieu, P. 2005a. "La dominación masculina revisitada". Archipiélago, Cuadernos de crítica de la cultura. Crisis de la beterosexualidad y reinvención de la condición bumana 67: 9-22.

Bourdieu, P. 2005b. La Dominación Masculina. Barcelona: Anagrama.

Brandes, S. 1991. Metáforas de la masculinidad: sexo y estatus en el folklore andaluz. Madrid: Taurus.

Butler, J. 1990. Gender trouble. Nueva York: Routledge.

Butler. J. 1993. Bodies that matter. On the discursive limits of 'sex'. Nueva York: Routledge.

Celis, B. 2011. "La 'Top Model' es un hombre", en http://www.elpais.com/articulo/agenda/top/model/hombre/elpepigen/20110605elpepiage_2/Tes. Consulta 10 de agosto de 2011.

Clarkson, J. 2008. "The limitations of the discourse of norms. Gay visibility and degrees of transgression". Journal of Communication Inquiry 32: 368-382.

Coles, T. 2009. "Negotiating the field of masculinity: The production and reproduction of multiple dominant masculinities". Men and Masculinities 12: 30-44.

Collier, M. 2001. "Approaches to Analysis in Visual Anthropology", en T. Van Leeuwen y C. Jewitt (eds), Handbook of Visual Analysis: 35-60. Londres: Sage.

Connell, R. W. 1995. Masculinities. Cambridge: Polity Press.

Connell, R. W. 1997. "Gender politics for men". International Journal of Sociology and Social Policy 17 (1/2): 62-77.

Connell, R. W. y J. W. Messerschmidt. 2005. "Hegemonic masculinity. Rethinking the concept". Gender \& Society 19: 829-859.

Demetriou, D. Z. 2001. "Connell's concept of hegemonic masculinity: A critique". Theory and Society. 30: 337-361.

Díaz de Rada, A. 2010. Cultura, antropología y otras tonterias. Madrid: Trotta.

Enguix, B. 1996. Poder y Deseo. Valencia: Alfons el Magnànim.

Enguix, B. 2000. "Sexualidad e Identidades".Gazeta de Antropología 16 (electrónica).

Enguix, B. 2009. «Identities, sexualities and commemorations: Pride parades, public space and sexual dissidence». Anthropological Notebooks XV: 15-35.

Enguix, B. 2010. "Fronteras, cuerpos e identidades gays". Quaderns de l'ICA 26: 83-107.

Enguix, B. 2011. "Cuerpo y Transgresión: De Helena de Céspedes a Lady Gaga”. Relaces, Revista Latinoamericana de Estudios sobre Cuerpos, Emociones y Sociedad 5 (3): 25-38.

Featherstone, M. 1982. "The Body in Consumer Culture". Theory, Culture and Society 1: 18-33.

Featherstone, M.; M. Hepworth y B. Turner (eds.). 1999. The Body: Social Process and Cultural Theory. Londres: Sage.

Foucault, M. 1984. Historia de la Sexualidad (I). La Voluntad de Saber. Madrid: Siglo XXI.

Foucault, M. 1991. Tecnologías del Yo. Barcelona: Paidós.

Galak, E. 2011. "Con Bourdieu y contra Bourdieu. Reflexiones sobre la relación habitus y cuerpo", en V. D'Hers y E. Galak (comps.), Estudios Sociales sobre el Cuerpo: Prácticas, Saberes, Discursos en Perspectiva: 38-56. Buenos Aires: Estudios Sociológicos.

García Cortés, J. M. 2004. Hombres de Mármol. Códigos de representación y estrategias de poder de la masculinidad. Madrid: Egales. 
Gibson, R. 2004. "Coverage of Gay Males, Lesbians in Newspaper Lifestyle Sections in Newspaper research Journal. Newspaper Research Journal http://findarticles.com/p/ articles/mi_qa3677/is_200407/ ai_n9432119/Consulta 2 de mayo de 2011.

Giddens, A. 1994. Modernidad e identidad del yo. El yo y la sociedad en la época contemporánea. Barcelona: Península.

Gilmore, D. D. 1994. Hacerse Hombre. Concepciones culturales de la masculinidad. Barcelona: Paidós.

Goffman, E. 1968. Estigma. La identidad deteriorada. Buenos Aires: Amorrortu.

Goffman, E. 1979. Gender Advertisements. Nueva York: Harper and Row.

Goffman, E. 1987. La presentación de la persona en la vida cotidiana. Madrid: AmorrortuMurguía.

Gómez, M. D. 2008. "El género en el cuerpo". IX Congreso Argentino de Antropología Social: "Fronteras de la Antropología", Posadas, Misiones, 5 al 8 de agosto de 2008. http:/ /www.antropologiadelcuerpo.com/index. php?option=com_content\&view=article\&id= 236\%3Ael-genero-en-el-cuerpo\&catid=69\%3Acuerpo-y-genero\&Itemid=61\&lang= pt\&showall $=1$ Consulta 15 de julio de 2011.

Hall, S.; D. Hobson; A. Lowe y P. Willis (eds.). 1980. Culture, Media, Language. Londres: Hutchinson.

Hall, S. 2003. Representation: Cultural Representations and Signifying Practices. Londres: The Open University Press /Sage.

Hennen, P. 2005. "Bear bodies, bear masculinity: Recuperation, resistance, or retreat?". Gender \& Society 19: 25-43.

Hennen, P. 2008. Faeries, bears and leathermen. Men in community. Queering the masculine. Chicago: The University of Chicago Press.

Herrmann, A. F. 2007. "People get emotional about their money: performing masculinity in a Financial Discusión board". Journal of Computer-Mediated Communication 12 (2).

Holt, M. y C. Griffin. 2003. "Being gay, Being straight and being yourself: local and global reflections on identity, authenticity and the lesbian and gay scene». European Journal of Cultural Studies 6: 404-425.

Howson, A. 2005. Embodying Gender. Londres: Sage.

Jefferson, T. 2002. "Subordinating hegemonic masculinity". Theoretical Criminology 6: 63-88.

Kerrell R. H. 1992. "The Symbolic strategies of Chicago's gay and lesbian pride day parade", en G. Herdt (ed.), Gay Culture in America. Essays from the Field. Boston: Beacon Press.

Kimmel, M. (ed.). 1987. Changing Men: New Directions in Research on Men and Masculinity. Nueva York: Sage.

Kimmel, M. 2000. The Gendered Society. Oxford: Oxford University Press.

Langman, L. 2003. "Culture, Identity and Hegemony: the Body in a Global Age». Current Sociology: 51 (3-4): 223-247.

Laqueur, T. 1994. La Construcción del Sexo. Cuerpo y Género desde los Griegos hasta Freud. Madrid: Cátedra.

Levine, M. P. 1998. Gay Macho. Nueva York: New York University Press.

List Reyes, M. 2005. "Hombres: cuerpo, género y sexualidad". Cuicuilco 33:173-202.

Locke, P. 1997. "Male images in the Gay Mass Media and Bear-oriented Magazines: Analysis and Contrast", en L. Wright (ed.), The Bear Book. Readings in the History and Evolution of a Gay Male Subculture: 103-141. Nueva York: Harrington Park Press.

Lusher, D. y G. Robins. 2009. "Hegemonic and other masculinities in local social contexts". Men and Masculinities 11: 387-423.

Marcel, G. 1935. Etre and Avoir. París: Aubier 
Moore, P. L. (ed.). 1997. Building Bodies. New Brunswick: Rutgers University Press.

Moreno Feliu, P. 2010 Encrucijadas antropológicas. Madrid: Ramón Areces.

Mosse, G. L. 1996. The Image of Man. Oxford: Oxford University Press.

Nixon, S. 2003. "Exhibiting Masculinity", en S. Hall (ed.), Representation: Cultural Representations and Signifying Practices: 291-337. Londres: The Open University PressSage.

O'Barr, W. M. 2008. "Representations of Masculinity and Femininity in Advertisements". Advertising and Society Review s.d.: 1-31.

Paasonen, S.; K. Nilunin y L. Saarinmaa (eds.). 2007. "Pornification. Sex and Sexuality", en Media Culture. Nueva York: Berg.

Pedraza, P. 2009. Venus barbuda y el eslabón perdido. Madrid: Siruela.

Pedraza Gómez, Z. 2003. "Cuerpo e Investigación en Teoría Social”, ponencia presentada en la Universidad nacional de Colombia, sede Manizales, en la Semana de la Alteridad http://antropologia.uniandes.edu.co/zpedraza/ zp1.pdf Consulta 10 de julio de 2011.

Pringle, R. L. 2005. "Masculinities, sport and power: A critical comparison of Gramscian and Foucauldian inspired theoretical tools". Journal of Sport and Social Issues 29: 256-278.

Ragusa, A. T. 2003. "Social Change in the Media: Gay, Lesbian, Bi, Trans and Queer (GLBTQ) Representation and Visibility in The New York Times. A Critical, Qualitative Social-Historical Content Analysis of The New York Times", en http://scholar.lib.vt.edu/ theses/available/etd-01232003-180107/unrestricted/Angelaragusadissert.pdf Consulta 10 de mayo de 2011.

Reyero, C. 1996. Apariencia e Identidad Masculina. De la Ilustración al Decadentismo. Madrid: Cátedra.

Rohlinger, D. A. 2002. "Eroticizing Men: Cultural Influences on Advertising and Male Objectification". Sex Roles 3 (4): 61-74.

Sabido Ramos, O. 2010. "El cuerpo y la afectividad como objetos de estudio en la Sociología. Ángulos de lectura en América Latina». Ponencia para el Congreso 2010 de la Asociación de EstudiosLatinoamericanos, Toronto, 6-9- octubre 2010. http:// lasa.international.pitt.edu/members/ congress-papers/lasa2010/files/2077.pdf Consulta 10 de julio de 2011.

Sáez, J. 2010a. "Excesos de la masculinidad: cultura leather y cultura bear". Mundo peluche: 1-10 (accesible en http://www.mundopeluche.tk/news/ excesos-de-la-masculinidad-cultura-leather-y-cultura-bear/ Consulta 7 de julio de 2011.

Sáez, J. 2010b. "Osos desplumados”, en www.bearspain.com/articulo_hartza.htm (Consulta 12 de diciembre de 2010).

Saucier, J. y S. L. Caron. 2008. "An Investigation of Content and Media Images in Gay men's magazines". Journal of Homosexuality 55 (3): 504-523.

Schulze, L. 1997. "On the Muscle", en P. L. Moore (ed), Building Bodies: 9-31. New Brunswick: Rutgers University Press.

Seidler, V. J. 2007. "Masculinities, bodies, and emotional life". Men and Masculinities 10: 9-21.

Sheff, E. 2006. "Poly-hegemonic masculinities". Sexualities 9: 621-642.

Shilling, C. 2005. The Body in Culture, Technology and Society. Londres: Sage.

Skeggs, B. 1997. Formations of Class and Gender. Londres: Sage.

Trumbach, R. 1993. “London's Sapphists: from three sexes to four genders in the making of modern culture", en G. Herdt (ed.), Third Sex, Third Gender: 111-136. Nueva York: Zone Books. 
Turner, B. S. 1984. Body and Society. Oxford: Basil Blackwell.

Vale de Almeida, M. 1996. The Hegemonic Male. Masculinity in a Portuguese Town. Oxford: Berghahn Books.

Van Zoonen, L. 1994. Feminist Media Studies. Londres: Sage.

Vázquez, F. y A. Moreno. 1997. Sexo y Razón. Una Genealogía de la Moral Sexual en España. Madrid: Akal.

Weeks, J. 1985. Sexuality and its Discontents. Meanings, Myths and Modern Sexualities. Londres: Routledge.

Wright, L. (ed.). 1997. The Bear Book. Readings in the History and Evolution of a Gay Male Subculture. Nueva York: Harrington Park Press.

Revistas:

- Cosmopolitan, julio 2011

- El País Semanal, núm. 1817, domingo 24 julio 2011

- Glamour, julio 2011

- GQ España, julio-agosto 2011

- H Magazine, julio-agosto 2011

- L’Uomo Vogue, ed. Italia, julio 2011

- Odisea, junio 2011

— Obmygod!, junio 2011

- Qué Guay, núm. 6/julio 2011

- Shangay Express, num. 406, 20 junio-4 julio 2011

- Shangay Style, núm. 12, verano 2011

- Shanguide, núm. 406, 20 junio- 4 julio 2011

- Tendencias, julio-agosto 2011

Fecha de recepción: 10 de octubre de 2011

Fecha de aceptación: 28 de febrero de 2012 